\title{
A serum-free medium for testing fermentation reactions in Neisseria gonorrhoeae
}

\author{
JOHN FLYNN AND SHEENA A. WAITKINS \\ From the Department of Medical Microbiology, The University of Sheffield, England
}

SYNOPSIS Gonococcal infections can no longer be considered exclusively urogenital but it is difficult in a busy routine laboratory to identify gonococci from non-genital sites, especially if other commensal neisseria are present. Unfortunately, conventional serum agar sugars sometimes give equivocal results. A fermentation medium is described for the identification of gonoccoci. On preliminary testing this medium gives rapid and reliable results and should prove to be much more helpful to the routine laboratory than conventional serum agar sugars. Its potential usefulness, as demonstrated by the results of our first 200 examinations, would seem to justify further study in the routine work of other laboratories.

Recent reports show that gonococcal infections can no longer be considered to be exclusively urogenital and the organisms may be found in sites such as the pharynx (Fiumara, Wise, and Many, 1967), tongue (Cowan, 1969), tonsils (Hellgren, 1971; Iqbal, 1971), and skin (Barr and Danielsson, 1971). The standard method used to identify neisseria is the fermentation reactions when tested against glucose, maltose, and sucrose. A disadvantage of the serum agar slopes of these sugars is that many laboratories find difficulty in interpreting the results owing to the occurrence of a non-specific change in the indicator which sometimes develops and often makes the interpretation of the maltose results impossible and, moreover, leads to a complete lack of confidence in the test. The identification of a suspected pathogen is always desirable but this will not be achieved when gonococci are isolated from sites where other neisseria are likely to be found, unless the fermentation tests employed are absolutely reliable. The existence of several alternative media today suggests that none has been found to be completely satisfactory.

Vera (1948) described a medium containing a pancreatic digest of casein which at first appeared to give reliable results, but it was shown later (White and Kellogg, 1965) that on this medium some strains of $N$. gonorrhoeae failed to grow, or grew poorly, whilst others grew but failed to ferment carbohydrate. A more satisfactory medium was developed at the Statens Seruminstitut, Copenhagen, which consisted of human placenta broth-ascitic fluidReceived for publication 2 February 1972. agar, plus carboxylase (Reyn, 1965). A new medium somewhat similar to that of Reyn, to which was added hemin, was developed by Juhlin (1963) and this has proved itself as a useful medium.

Such media may be ideal for a large specialized unit but are less suitable for smaller routine laboratories. They are tedious to prepare and the use of human biological fluids such as serum, hydrocele fluid, or placenta extracts may present the hazard of hepatitis or other infections to the technical staff.

White and Kellogg (1965) described a new medium consisting of a proteose peptone agar to which was added glutamine, cocarboxylase, and ferric nitrate. Despite the good results they reported, the medium is still not in common use. Cocarboxylase, being heat labile, must be added as a sterile solution after the other constituents have been autoclaved. Most workers will have been reluctant to omit the cocarboxylase, as Lankford (1946) claimed that if this was omitted a small percentage of fastidious strains of gonococci would not grow.

\section{Materials and Methods}

As Difco GC medium base $+2 \%$ defined supplement, consisting of ferric nitrate, L-glutamine, cocarboxylase, and glucose (White and Kellogg, 1965 ), is routinely used for the growth of $N$. gonorrhoeae in our laboratory, it seemed a reasonable start to see if the incorporation of sugars into this medium would give a satisfactory fermentation medium. A number of workers, including White 
and Kellogg, believed that cocarboxylase was necessary, so we decided to test batches of Difco GC medium base containing only L-glutamine and ferric nitrate, with and without the addition of cocarboxylase. As preliminary results were the same on both media, we decided to omit the cocarboxylase.

\section{MEDIA}

Difco GC medium base

$\begin{array}{lllll}\text { Proteose peptone no. } 3 & \text {. } & \text {. } & \text {.. } & 15 \mathrm{~g}\end{array}$

$\begin{array}{llllll}\text { Corn starch } & \ldots & \ldots & \ldots & \ldots & 1 \mathrm{~g}\end{array}$

Di-potassium phosphate $\quad . . \quad \ldots \quad 4$ g

Potassium di-hydrogen phosphate $\quad . . \quad 1$ g

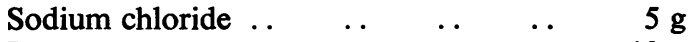

$\begin{array}{llllll}\text { Bacto agar } & \ldots & \ldots & \ldots & \ldots & 10 \mathrm{~g}\end{array}$

Distilled water $\quad . \quad \ldots \quad \ldots \quad \ldots \quad \ldots \quad 1000 \mathrm{ml}$

SUPPLEMENT

This is prepared by adding $90 \mathrm{ml}$ of $\mathrm{A}$ to $10 \mathrm{ml}$ of $\mathrm{B}$ :

\section{A Glutamine solution}

Dissolve $1 \mathrm{~g}$ of L-glutamine in $90 \mathrm{ml}$ of distilled water.

\section{B Ferric nitrate}

Ferric nitrate, $0.05 \mathrm{~g}$, was dissolved in $10 \mathrm{ml}$ of distilled water.

PHENOL RED

$0 \cdot 2 \%$ stock solution.

\section{SUGARS}

Ten per cent solutions of either glucose, sucrose, or maltose which are sterilized by Seitz filtration.

The fermentation medium was prepared by boiling $36 \mathrm{~g}$ of the $\mathrm{GC}$ medium base in $970 \mathrm{ml}$ of distilled water and adding, when clear, $20 \mathrm{ml}$ of the supplement and $10 \mathrm{ml}(0.2 \%)$ of phenol red solution. The $p \mathrm{H}$ of the medium was adjusted to 7.6 with $\mathrm{N} . \mathrm{NaOH}$, and it was then distributed in $90 \mathrm{ml}$ volumes into $4 \mathrm{oz}$ screw cap bottles, which were autoclaved at $15 \mathrm{lb}$ for 10 minutes. After cooling to $50^{\circ} \mathrm{C}, 10 \mathrm{ml}$ of the appropriate sugar was added aseptically to give a final concentration of $1 \%$. Three ml amounts were dispensed into sterile bijoux bottles and sloped. The sugars were identified by a colour code on the caps.

Thus, the trial medium contained Difco GC base, L-glutamine, ferric nitrate, and the appropriate substrate, ie, glucose, maltose, or sucrose. The addition of vancomycin $3 \mu / \mathrm{ml}$ and colomycin $8 \mu / \mathrm{ml}$ was considered, but we decided that these are unnecessary as only pure cultures should be used for identification of strains.

\section{BACTERIAL CULTURES}

One hundred strains of $N$. gonrrohoeae were exam-음 ined, $70 \%$ of which had been recently isolated from patients attending VD clinics in the Sheffield area, and the remainder being earlier isolates which had been stored in liquid nitrogen for periods rangingo from three to 24 months. In addition, we tested $\frac{}{5}$ three strains of $N$. meningitidis and the followinge five strains of commensal neisseria obtained from the National Collection of Type Cultures, London:-

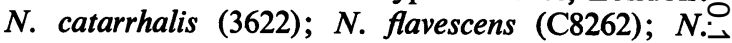
pharyngis (4591); N. animalis (10202); and N. caviae $\vec{\omega}$ (10292).

All bacteria were grown on $5 \%$ lysed horse blood용 agar for 18 hours and purity was checked by Gramin staining and a positive oxidase reaction. A slope of new fermentation medium and a standard serumir agar slope were heavily inoculated with each tester organism and incubated at $37^{\circ} \mathrm{C}$ in 'candle jars'음 with the screw caps loose. The fermentation reactions were observed over a period of 48 hours. $\subseteq$ The advantage of heavy inocula was that positive results could be read as early as eight to 12 hours. $\overrightarrow{0}$ However, the medium will give positive results with very small inocula and we obtained typical fermentation reactions after 60 hours with as fewo as 150 organisms $/ \mathrm{ml}$.

\section{Results}

Table I shows the comparative results of fermenta- 3 tion reaction of $N$. gonorrhoeae on standard serum? agar sugars and the test medium.

\begin{tabular}{|c|c|c|c|c|c|}
\hline \multirow[t]{2}{*}{ Medium } & \multirow{2}{*}{$\begin{array}{l}\text { No. of } \\
\text { Strains } \\
\text { Tested }\end{array}$} & \multirow{2}{*}{$\begin{array}{l}\text { Time of } \\
\text { Incubation } \\
\text { (hr) }\end{array}$} & \multicolumn{3}{|c|}{$\begin{array}{l}\text { No. of Strains Interpreted } \\
\text { as Showing Acid Production }\end{array}$} \\
\hline & & & Glucose & Maltose & Sucrose \\
\hline $\begin{array}{l}\text { Serum } \\
\text { agar } \\
\text { Test } \\
\text { media }\end{array}$ & $\begin{array}{l}100 \\
100\end{array}$ & $\begin{array}{l}24 \\
48 \\
24 \\
48\end{array}$ & $\begin{array}{r}79 \\
100 \\
97 \\
100\end{array}$ & $\begin{array}{r}21 \\
21 \\
0 \\
0\end{array}$ & $\begin{array}{l}\mathbf{0} \\
\mathbf{0} \\
\mathbf{0} \\
\mathbf{0}\end{array}$ \\
\hline
\end{tabular}

Table I Comparison of the fermentation reactions of N. gonorrhoeae on serum agar sugars and on test media

Table II shows the fermentation reactions of thew reference strains of neisseria.

On serum sugar media 11 strains failed to utilize glucose in 24 hours but all were positive after 480 hours; however, 21 strains gave what must be inter - preted as positive maltose reactions. All the other neisseria species listed in Table II gave typical suga? fermentation patterns on both media.

Three of the 100 strains of $N$. gonorrhoeaß examined failed to utilize glucose on the test mediump 


\begin{tabular}{|c|c|c|c|c|c|c|c|}
\hline \multirow[t]{2}{*}{ Organism } & & \multicolumn{3}{|c|}{$\begin{array}{l}\text { Acid Production after Incubation } \\
\text { for } 48 \text { Hours (serum agar) }\end{array}$} & \multicolumn{3}{|c|}{$\begin{array}{l}\text { Acid Production after Incubation } \\
\text { for } 48 \text { Hours (test media) }\end{array}$} \\
\hline & & Glucose & Maltose & Sucrose & Glucose & Maltose & Sucrose \\
\hline$N$. meningitidis & C453 & + & + & - & + & + & - \\
\hline N. meningitidis & C587 & + & + & - & + & + & - \\
\hline N. meningitidis & C466 & + & + & - & + & + & - \\
\hline N. catarrhalis & (3622) & - & - & - & - & - & - \\
\hline N. favescens & C8262 & - & - & - & - & - & - \\
\hline N. pharyngis & (4591) & + & + & d & + & + & d \\
\hline$N$. animalis & (10212) & $\mathrm{d}$ & - & + & $\mathrm{d}$ & - & + \\
\hline N. caviae & (10293) & - & - & - & - & - & - \\
\hline
\end{tabular}

Table II Fermentation reactions of neisseria species for both serum agar sugars and test media

$+=$ acid production; $-=$ no acid production; $d=$ doubtful.

after 24 hours' incubation. All, however, fermented glucose after 48 hours. Neither sucrose nor maltose was fermented by any of the test organisms.

\section{Discussion}

The need for a simple and consistently reliable medium for testing fermentation reactions in the identification of neisseria species has long been recognized. The interpretation of results using serum agar sugars in the identification of gonoccoci is complicated by a large number of false positive maltose reactions. In this series of experiments we set out to develop a medium which would grow the organisms well but eliminate false fermentation reactions. Subsequently, we have brought it into routine use and examination of a further 100 fresh isolates confirms our hopes of its usefulness.

The results obtained so far indicate that this medium has advantages over serum agar sugars, especially in the interpretation, as the problem of false positive maltose reactions does not appear to arise. Positive reactions may be read after eight hours' incubation and the medium is easier to prepare. One possible disadvantage may be presented by strains of gonococci which require cocarboxylase for growth. So far, we have not encountered any cocarboxylase-sensitive strains, but if any do occur the problem they present could be overcome by adding the appropriate concentration of cocarboxylase directly to the sugar solutions (and subsequently incorporating both into the medium.) The total shelf life of the medium must be assessed, but is certainly long enough to be useful, and the possibility of using this medium for other fastidious organisms may be considered.

This work was supported by a grant from the Medical Research Council. We wish to thank Professor M. G. McEntegart for his invaluable help in preparing this manuscript. We are grateful to $\mathrm{Dr}$ R. S. Morton and to colleagues at the Public Health Laboratory, Northern General Hospital, for strains of gonococci, and also to Miss Anne Littlewood for invaluable technical help.

References

Barr, J., and Danielsson, D. (1971). Septic gonococcal dermatitis. Brit. med. J., 1, 482-485.

Cowan, L. (1969). Gonococcal ulceration of the tongue in the gonococcal dermatitis syndrome. Brit. J. vener. Dis., 45, 228-231.

Fiumara, N. J., Wise, H. M., Jr., and Many, M. (1967). Gonorrheal pharyngitis. New Engl. J. Med., 276, 1248-1251.

Hellgren, L. (1971). Gonorrhoea and tonsillitis following genito-oral contact. Lakartidningen, 68, 569-571.

Iqbal, Y. (1971). Gonococcal tonsillitis. Brit.J. vener. Dis., 47, 144-145.

Juhlin, I. (1963). A new fermentation medium for N. gonorrhoeae, HAP-medium. Influence of different constituents on growth and indicator colour. Acta path. microbiol. scand., 58, 51-71.

Lankford, C. E., and Skaggs, P. K. (1946). Co-carboxylase as a growth factor for certain strains of Neisseria gonorrhoeae. Arch. Biochem. 9, 265-283.

Reyn, A. (1965). Laboratory diagnosis of gonococcal infections. Bull. Wld Hlth Org., 32, 449-469.

White, L. A., and Kellogg, D. S., Jr. (1965). An improved fermentation medium for Neisseria gonorrhoeae and other neisseria. Hlth Lab. Sci., 2, 238-241.

White, L. A., and Kellogg, D. S., Jr. (1965). Neissera gonorrhoeae identification in direct smears by a fluorescent antibodycounterstain method. Appl. Microbiol., 13, 171-174.

Vera, H. D. (1948). A simple medium for the identification and maintenance of the gonococcus and other bacteria. J. Bact., $55,531-536$. 